\title{
Trump, Snakes, and the Power of Fables
}

\section{Katharina Stevens}

\author{
Philosophy Department \\ University of Lethbridge \\ Lethbridge, AB T1K $3 M 4$ \\ katharina.stevens@uleth.ca
}

\begin{abstract}
At a recent rally, Donald Trump resumed a habit he had developed during his election-rallies and read out a song telling the Aesopian fable of The Farmer and the Snake. In this paper, I assume that Trump treats the fable as an argumentative device to support his stance on immigration. This gives me the opportunity to examine the effect fables have as argumentative devices. Fables are slimmed down, semi-abstract narratives, well suited for directing the audience's attention. However, this also makes it easy to use them to manipulate an audience into oversimplifying contexts and dehumanizing human beings.
\end{abstract}

Résumé: Lors d'un rassemblement récent, Donald Trump a repris une habitude qu'il avait développée lors de ses rassemblements électoraux et a lu une chanson racontant la fable d'Ésope, Le laboureur et le serpent. Dans cet article, je suppose que Trump traite la fable comme un moyen argumentatif pour soutenir sa position sur l'immigration. Cela me donne l'occasion d'examiner l'effet que les fables ont comme moyens d'argumentation. Les fables sont des récits réduits et semi-abstraits bien adaptés pour diriger l'attention du public. Cependant, cela facilite également leur utilisation pour manipuler un auditoire à simplifier à l'excès des situations complexes et à déshumaniser des êtres humains.

Keywords: analogy, Donald Trump, fables, narrative argument

\section{Donald Trump gives a dramatic reading}

On the $29^{\text {th }}$ of April 2017, at a rally in Harrisburg, Pennsylvania, Donald Trump reads out the lyrics of a song. The song, "The Snake", was written by Al Wilson and released in $1968 .{ }^{1}$

${ }^{1}$ Trump's reading of "The Snake” by Al Wilson (1968) took place on April 29, 2017, in Harrisburg Pennsylvania. See:

https://www.youtube.com/watch?v=40iJUAHej14 esp. 42:10-46:05

(C) Katharina Stevens. Informal Logic. Vol. 38, No.1 (2018), pp. 53-83. 
The story told in the song is much older than the song itself. It is a version of the Aesopian Fable of The Farmer and The Snake (or The Farmer and The Viper, number 176 in the Perry Index). ${ }^{2}$ In the version Trump reads, the farmer is transformed into a "tenderhearted woman" who finds the "vicious" snake half-frozen on her way to work. The snake pleads for help, appealing to the woman's tender-hearted nature, and she is moved immediately. She wraps the snake in a silk-comforter and lays it by the fire in her house. When she hurries home from work that day, the snake has regained its health. In great joy, she hugs and kisses it and strokes its skin. But instead of thanking her for its life, the snake bites her. When she cries out and asks why the snake would kill her, it answers: "Oh shut up, silly woman (...) You knew damn well I was a snake before you took me in" (Wilson 1968). In other versions, the fable is followed up with a moral that suggests that kindness to evil will be met by betrayal, but Trump does not state one.

As he had done in earlier rallies, Trump provides the lyrics as a comment on immigration, likely both on undocumented immigrants that enter the U.S. over its southern border and on immigrants of Islamic faith: Immediately preceding the reading, as he has done before, he gives lengthy anecdotes about crimes committed by both groups. ${ }^{3}$ He introduces the fable by saying: “... this was written by Al Wilson a long time ago and I thought of it having to do with our borders and people coming in and we know what we are going to have. We are going to have problems. We have to very, very carefully vet. We have to be smart, we have to be vigilant. So here it is, the snake. It's called the snake." After he has read the fable, he continues: "Does this explain it folks? Does that explain?"4 Loud clapping and cheering documents his audience's approval.

In this paper, I discuss Trump's use of the fable, assuming it ha argumentative purpose. I claim that the fable has two different

\footnotetext{
${ }^{2}$ One version of the fable can be found in:

http://mythfolklore.net/aesopica/perry/176.htm (accessed July 7, 2017)

${ }^{3}$ See below for a more detailed description of these anecdotes. Trump uses this strategy, for example, in his rallies in: Harrisburg, April 29, 2017; Cedar Falls Iowa, January 12, 2016; and Estero Florida, September 19, 2016.

${ }^{4}$ Trump, Rally in Harrisburg, Pennsylvania, April 29, 2017
} 
effects in this context. In both cases, it serves as part of an argumentative analogy. First, it directly supports the conclusion that immigrants pose a risk of substantial harm to Americans (and thereby that the much harsher vetting policies Trump wants to see implemented are necessary). Second, it does argumentative work in a broader sense by influencing the frames within which Trump's audience will think about a whole number of issues related to immigrants and those willing to help them. This second effect is the more wide-reaching one, even though it is less directly argumentative. It influences the reasoning his audience will engage in later and on surrounding issues by establishing a connection between immigrants and viciousness, as well as between the idea of being moved to help and naïveté. Trump not only gains the assent of his audience for policies he is advocating now, he also enhances the probability that they will assent to policies that appear to mitigate risks from immigrants later on. This means that he uses the fable for a kind of multi-purposive argumentation, broadly understood as Dima Mohammed uses the term: He makes an argumentative move that will influence several discussions touching on topics around immigration at once-though the exact topics of some of these discussions might not yet even be known to either Trump or his audience (Mohammed 2015, 2016).

I argue that both uses of the fable as an argumentative sourceanalogue are problematic and that this case illustrates one reason why fables in argumentative analogies are easily abused for illegitimate manipulation. The special narrative form of the fable makes it potent as an argumentative source-analogue, but also as a manipulative tool. Fables portray specific narratives in a highly concentrated, semi-abstract way in order to illustrate "truths" about very limited issues. As source-analogues, this makes them especially convenient for influencing the presence $e^{5}$ that aspects of a subject

${ }^{5}$ The concept of presence is a rhetorical concept. An idea, for example, has
presence in the mind of an audience if it is in the forefront of their mind, so that
they are likely to use it in their reasoning and likely to accept it as a premise for
arguments they might come to hear. Many people living near the Rocky Moun-
tains, for example, know a number of things about wolves. For most people,
however, the most present idea about wolves is that they are dangerous - rather (c) Katharina Stevens. Informal Logic. Vol. 38, No.1 (2018), pp. 53-83. 
matter have in an audience's mind. But it also makes them an excellent tool for leading an audience into oversimplifying complex issues and reducing human beings to stereotypes.

\section{2. "The Farmer and the Snake" - a typical fable}

Fables are fictional narratives in which a particular plot is used to present a general, but tightly circumscribed aspect of human experience, often a kind of behaviour, attitude or world-view and its consequence. ${ }^{6}$ While fables can be delivered in different waysthey have been presented in rhymed form, ${ }^{7}$ extremely short bits of prose ${ }^{8}$ or book-long texts ${ }^{9}$ - they are distinguishable from other kinds of narratives (novels, epic poems, fictionalized biographies, parables, etc.) through their particular use of literary devices as well as their composition of the protagonists and plot. Typically, these factors are single-mindedly chosen to isolate and present the very limited general truth that the fable is meant to show (Blackham 1985, Chapter 5-reprinted 2013; Lessing 1759). For example, that fables often employ specific animals as characters is a device for isolating the issue portrayed by the fable from other issues. As Lessing pointed out long ago, animals can serve as instantiations of human stereotypes (Lessing 1759): the fox is cunning, the lamb innocent, the snake evil. The use of specific animals in fables allows the reader to identify the human character-trait(s)

than, for example, the idea that they are a protected species or that they are an important component of the Rocky Mountain eco-system. If an arguer wants to use a premise in an argument, she does well to ensure that the premise is present to her audience before she describes her inferences. For work dealing with the rhetorical concept of presence see, e.g. (Perelman and Olbrechts-Tyteca 1969, pp. 116 ff.; Perelman 1982, pp. 35 ff; Tindale 2015, chapter 10).

${ }^{6}$ Unlike parables (and some moralizing children's books), fables do not usually deliver a moral lesson. Rather, they simply portray what kinds of behaviours and character traits will lead to what kinds of outcomes, lending themselves much more to prudential lessons (and often the moral of the fable is not actually moral, but instead prudential). For further remarks on this, see footnote 11.

${ }^{7}$ For example, Fontaine's fables (see, e.g. Fontaine (ed. Marsh), 2001)

${ }^{8}$ This is how re-tellings of Aesop's fables are often presented.

9 George Orwell's Animal Farm is often regarded as such a long fable (Orwell 2008).

(C) Katharina Stevens. Informal Logic. Vol. 38, No.1 (2018), pp. 53-83. 
and motive(s) laid out for their consideration. Thereby, the fable gets rid of the complications of having real human protagonists with complex motives and interests.

Even where no animals are used, the fable employs onedimensional characters that exemplify only very few charactertraits. The plot of the fable and the circumstances in which its protagonists operate are also chosen not to document the way things really happen, but to provide a rationale for bringing them together to interact. The fable therefore portrays the general by using particulars that have no properties that would make them distinguishable from other particulars in their general class. Instead of delivering its message by talking in the abstract about universals, the fable tells a particular narrative, but a narrative without distinguishing attributes, which is why Blackham calls fables "semiabstract" (Blackham 1985, p. 203). He provides the following example: 'In 'The Fox and the Crow', the Fox is any agent of cunning (or diplomacy), the Crow any susceptible party in possession of something coveted, the flattery is grossly implausible (...). Thus the kind of behaviour is seen, memorably" (Blackham 1985, p. 177). ${ }^{10}$

Trump's version of The Farmer and the Snake is a typical example of how fables isolate a single issue. There, the character-

${ }^{10}$ A Fox once saw a Crow fly off with a piece of cheese in its beak and settle on a branch of a tree.

"That's for me, as I am a Fox," said Master Reynard, and he walked up to the foot of the tree.

"Good day, Mistress Crow," he cried. "How well you are looking today: how glossy your feathers; how bright your eye. I feel sure your voice must surpass that of other birds, just as your figure does; let me hear but one song from you that I may greet you as the Queen of Birds."

The Crow lifted up her head and began to caw her best, but the moment she opened her mouth the piece of cheese fell to the ground, only to be snapped up by Master Fox.

"That will do," said he. "That was all I wanted. In exchange for your cheese I will give you a piece of advice for the future: "Do not trust flatterers." (from: http://www.eastoftheweb.com/short-stories/UBooks/FoxCrow.shtml accessed July, 25 2017)

(C) Katharina Stevens. Informal Logic. Vol. 38, No.1 (2018), pp. 53-83. 
traits are not only alluded to through the choice of protagonists, ${ }^{11}$ but are spelled out directly: The snake is vicious and the woman tender-hearted. The content of the fable is the portrayal of what happens if behaviours motivated by these character-traits come together through a particular plot. The circumstance- that the snake is in trouble and needs help - is chosen only to kick off the interaction of the two character-traits that are of interest.

One interesting corollary of their semi-abstract nature is that fables stand somewhere between stories and story schemes, as analysts like Bex (2009), Bex and Verheij (2011), and Walton (e.g., 2012) use when analyzing argumentative narratives. Stories portray particular actions and events that we recognize as realistic, joined together in a sequence. By contrast, story schemes contain variables wherever elements are exchangeable without destroying the general structure. By filling in the variables, they can be turned into different stories, all of which recognizably belong to the same type. Fables, with their stripped-down protagonists and plots contain little in addition to such a scheme. Bex and Bench-Capon show this with the example of the fable of the Ant and the Grasshopper, which, according to them, could be turned into a story about a Squirrel and Hare without loss because the necessary stereotypical properties are shared by the grasshopper/hare and the squirrel/ant (Bex and Bench-Capon 2017, p. 41). In The Farmer and the Snake, the word 'snake' could be replaced with the variable V(x) (with the $\mathrm{V}$ standing for vicious) with equally little loss. ${ }^{12}$

From this, it follows that the fable does not try to show us human nature as a whole, or even the ways in which human beings, as

\footnotetext{
${ }^{11}$ Nothing could be further from me than to enforce stereotypes about women, but Al Wilson's choice to turn the farmer into a woman is most likely not accidental. Stereotypes about women portray them as more emotional, more susceptible to pity, and less rational than men. It also calls to mind another famous narrative involving a woman giving into a snake's wishes - the biblical story of Eve and the snake.

${ }^{12}$ I should mention here that, as Olmos (2014, p. 199-201) points out, not every text that has been classified as a fable is equally typical. Some fables have properties that make them less abstract. For example, some fables use their animals in surprising, non-stereotypical ways - for a number of examples see Blackham (1985, p. 11)
} 
whole characters, will react to certain circumstances. It therefore fails to deliver exactly what Martha Nussbaum praises as the great contribution of literature to reasoning-the ability to understand other people in foreign circumstances and thereby to learn how to value their experiences and understand where their actions come from (Nussbaum 1995). This special nature of fables has consequences when they are used argumentatively.

\section{The fable as an argument for its general message}

Fables always have a message that is supposed to be shown as true, so they lend themselves easily to an interpretation as argumentative narratives. However, their semi-abstract form, which enables their concentration on a single issue, has implications for how we should approach fables as arguments. To some degree, we can handle them in the same manner as other narratives by using the argumentscheme Gilbert Plumer developed for novels as arguments:

(1) This story (complex) is believable.

(2) This story is believable only if such and such principles operate in the real world.

(3) Therefore, such and such principles operate in the real world. (Plumer 2015, p. 498)

According to Plumer's analysis, the fable argumentatively supports its message by way of its overall believability. The fable of the snake succeeds in convincing us that kindness to evil will be met by betrayal because the story it tells is believable. However, the special nature of the fable changes the criteria it has to meet in order to cross the threshold to believability.

When speaking about novels, Plumer offers two criteria for believability: Internal coherence, or that the events in the narrative must be connected amongst each other, and external coherence, or that the narrative has to be consistent with our knowledge about human psychology and society (Plumer 2015). Writing about fictional narratives in general, Fisher offers a similar pair of criteria, namely coherence (Plumer's internal coherence) and fidelity (Plumer's external coherence) (Fisher 1987, 47). However, Olmos 
argues that a closer look reveals that Fisher's two criteria are actually split into several more. Having added criteria from other sources, she offers a long list that, according to her, could be expanded further:

1. Internal plot or structural coherence

2. Internal characterological coherence (Fisher, Cicero)

3. Internal degree of detail: expositio argumentosa, covering the seven or more circumstances: i.e. a rich enough, dense enough account (Agricola, Cicero)

4. Arguer-related, "ethotic" assessment: story/storyteller coherence (Fisher)

5. Coverage of relevant extra-diegetic evidence ("material coherence"). Relative to argumentative practice involved (Pennington and Hastie).

6. Uniqueness, situation of the story regarding other "competing" discourses (Pennington and Hastie).

7. Independence regarding other competing discourses (relative contribution to a collective reconstruction of plausibility based on multiple-source confirmation) (Olmos).

8. Audience-related, "pathotic" assessment: previous beliefs of audience. Relative to argumentative practice involved (Cicero).

9. External coherence, fidelity to the real, extra-diegetic world. Degree of realism (a complicated issue in itself).

10. Fidelity to human values: reliability and applicability of the story. Degree of humanism: ethical assessment (Fisher, Cicero). (Olmos 2015, p. 163)

Reading through this list, it becomes clear that there are some criteria that will make sense for narratives like novels or short stories, but not for fables. Fables are not meant to provide a rich account with a great degree of detail (criterion 3), nor do they portray the human character in its actual complexity (criterion 2, 
depending on interpretation). Where they make only descriptive points (as they often do), ${ }^{13}$ they are not up for ethical assessment (criterion 10). They are also not necessarily realistic, in that real actors will never be as one-dimensional as the semi-abstract characters in fables (criterion 9). Granted, it remains plausible to think that the fable has to meet Plumer's two criteria in order to support its message: its plot has to hang together and it has to work with what we know of the world. But because a fable does not aim at portraying the world as it is, but merely at showing the interplay of very specific and tightly circumscribed aspects of it, the requirements for believability are relaxed: A fable has to be externally coherent only in so far as we are not disappointed in our expectations about how the chosen character-traits will manifest themselves in behaviour. Further, in order to focus the attention on the exact aspects it is interested in, a fable's plot and characters are so slimmed down that it is internally coherent already if the interplay between the behaviours motivated by these character-traits will lead to effects that make sense. This is legitimate because and insofar as the fable makes a claim only about the interplay of the very limited aspects of the world it sets out to describe - but not about what happens when these aspects interact with the whole

\footnotetext{
${ }^{13}$ A fable's message is not (necessarily) the same as, and is certainly not limited to, the moral that is often attached to it and that is typically normative. These morals are sometimes missing (Olmos, 2014) and have usually been attached to the fable later (Blackham 1985, pp. xviii/xix, Hunt 2009, p. 377). Blackham observes that especially Aesopian fables seem to make descriptive rather than normative points if they are read without the moral. They are meant to show how things are, what is going to follow from certain types of behaviour, and the failures or successes certain attitudes will lead to (Blackham, 1985, p. 251). This might be one of the characteristics that distinguishes fables from parables as de Bustos (2017) describes them - parables are often used to deliver a normative message, fables are meant primarily to make a descriptive point. Implications for how people should behave become available only once additional premises are added. Taken without its moral, the fable of the snake merely portrays the ways in which tender-heartedness and viciousness will interact and who will prevail in this kind of interaction. The normative upshot of the story seems to be clear-do not help those who are evil- but only if we presuppose that prudential considerations prevail.
} 
complexity of life. While one-dimensional characters and a cutand-dry plot severely detract from the believability of a novel, they are part of what makes a fable work. The Farmer and the Snake does not portray the interaction of two real persons, one who isamong other things - tender-hearted and one who is - among other things - vicious. It portrays the interaction of these character-traits personified. Good fables succeed in isolating character-traits and showing the outcome of their interaction in an almost analytical fashion, as following somewhat necessarily. The Farmer and the Snake is highly believable not in spite of, but because of, its semiabstractness. Tender-heartedness manifests in kind actions, viciousness in vicious actions, and the outcome of the interaction is that the vicious is treated kindly, but the kind viciously. ${ }^{14}$

This is, I think, a good reason to reject Govier and Ayers' argument that fables (which they count among parables) do not make for good arguments by instantiation. Govier and Ayers argue that parables show highly specific and unique situations that are likely ill-suited to represent an entire class. At least for fables, this is not true. A well composed fable is neither highly specific nor unique in the relevant sense. It is stripped of everything that would make the situation it portrays truly unique exactly in order to portray an entire class effectively (Govier and Ayers 2012, p. 27).

\section{4. "The Farmer and the Snake" as a source-analogue}

When it comes to fables as arguments for general truths, their limitations do not pose a problem for their worth as arguments. Good fables make for good Plumerian arguments for very modest conclusions, conclusions only about the limited issue that they shine their spotlight on (Blackham 1985, 199). However, as Trump's use of The Farmer and the Snake demonstrates, fables can

\footnotetext{
${ }^{14}$ As one of my reviewers has pointed out, this means that one argumentative use of fables is to establish Toulmenian warrants (Toulmin 1969): If the fable is convincing, then this means that there is reason to accept a general, but defeasible if-then statement with a limited range of applicability. The warrant can then be used in various other, defeasible arguments.
}

(C) Katharina Stevens. Informal Logic. Vol. 38, No.1 (2018), pp. 53-83. 
also be used argumentatively as source-analogues. ${ }^{15}$ Eduardo de Bustos has pointed out that this can happen in two ways, both of which are exemplified in Trump's fable (de Bustos 2017, p. 96). First, fables can be source-analogues ${ }^{16}$ for arguments by analogy meant to support a specific conclusion. Second, they can be used as source-analogues in frame-setting analogies. In this form, they are not meant to support a specific claim. However, in this case they still fulfill an argumentative function by establishing a certain frame for their target-analogue, thereby influencing the way the audience will reason about it later.

Unlike the use of fables as Plumerian arguments, I argue that the use of fables as source-analogues risks crossing the line into manipulation. As I will argue, analogies are effective in making arguments accessible by foregrounding aspects conducive to the argument and backgrounding those that might distract or detract from the argument. Fables, with their concentrated, simplified characters and plots can all-to easily be used to intensify this effect to the point were an audience is led to oversimplify highly complex matters and to de-humanize people by reducing them to single character-traits. Well-written fables (as those by Aesop, Fontaine, Lessing, etc.) are highly believable and memorable and therefore stay

\footnotetext{
${ }^{15}$ Lessing, in his Abhandlung ueber die Fabel (1759), makes a distinction between simple and composite fables - fables by themselves and fables presented together with a real-life case for which they are meant to serve as sourceanalogues. His distinction is important, but I think that it shows two different (argumentative) uses for fables rather than two different kinds of fables. On the one hand, fables can be presented by themselves to support certain general truths about specific aspects of human experience. On the other, they can also be used to make a point about a specific issue or situation for which they then function as a source-analogue. This use of fables has a long tradition and is possibly as old as the use of fables themselves. For example, Aristotle describes the fable of the fox who was tormented by ticks but did not want to rid himself of them lest they be replaced by hungrier ones, as a piece of advice Aesop gave the Samians about how to deal with their already rich demagogue (Aristotle 2010, 2:20).

16 The "source-analogue" is the "phoros" in Perelman's terminology, and the "target-analogue" is Perelman's "theme" (Perelman 1982). The term "source-" and "target-" analogue are now more generally in use since they have been adopted by the leading account of analogical reasoning in the cognitive sciences, which is also used here (see, e.g. Holyoak and Thagard, 1995).
} 
with an audience for a long time, influencing their view on the target-analogue. This is the underlying problem in Trump's use of The Farmer and the Snake.

Despite the risks of using fables as source-analogues, fables are a popular choice for analogies, to the point where some theorists have proposed that fables always function as source-analogues. ${ }^{17} \mathrm{I}$ argue that this is not surprising. There are good reasons to think that fables as source-analogues are especially effective rhetorical tools. The Farmer and the Snake certainly is. A short and simplified look into the way we process analogies and the resulting rhetorical effects of well-chosen source-analogues will explain why.

According to the model of analogical reasoning that still provides the basis for research on analogy in the cognitive sciences, we process and understand analogies through the performance of so-called analogical mapping (See, e.g. Holyoak and Thagard 1989, 1995. See also Genter 1983). Mapping is the establishment of correspondences between elements of the two analogues, the source-analogue and the target-analogue. In Trump's use of the snake-fable, the fable is the source-analogue and America's interaction with its (potential) immigrants the target-analogue. To understand Trump's analogy, his audience maps the two analogues together by trying to find elements in the target-analogue that correspond to the elements in the source-analogue, for example the woman, the snake, and the plea for help. In choosing the correspondent for an element of the source-analogue, reasoners typically attempt to fulfill so-called surface and structural constraints. To fulfill the surface constraint, they try to find elements in the targetanalogue that can be categorized under the same categories (the narrower the better) as the elements in the source-analogue or that have similar perceptual qualities (Holyoak and Thagard 1995, pp. $26 \mathrm{ff}$.). The snake's plea, for example, can be categorized under

\footnotetext{
${ }^{17}$ Hunt argues that fables always function as source-analogues and that arguments based on fables are therefore arguments by analogy (e.g. Hunt 2009). However, as several authors have convincingly argued (Lessing 1759; Blackham 1985; Govier and Ayers 2012; Olmos 2014) this is a misconception because by themselves, fables lack a target-analogue and are meant to portray a general truth, rather than say something about a single target-case.
}

(C) Katharina Stevens. Informal Logic. Vol. 38, No.1 (2018), pp. 53-83. 
"asking for help" and so can the immigrant's petitions to enter America. Considerably more important for the success of an analogy is the structural constraint. To fulfill this constraint, reasoners attempt to map every element of the source-analogue to one and only one element in the target-analogue. In addition, if two elements stand in a certain relation in the source-analogue, the same (or similar, according to the surface constraint) relations need to be found in the target-analogue between the two corresponding elements (Holyoak and Thagard 1995, pp. 29ff.). In the fable, snake and woman stand in the relations of plea-maker and receiver, helped and helper, and finally, biter and bitten. To map these relations according to the structural constraint, immigrants have to be chosen as the equivalent of the snake, and America as the equivalent of the woman. Finally, there is the purpose constraint. The purpose constraint determines that those elements will be chosen for attempted mappings that are relevant in the source-analogue with respect to the purpose for which the analogy is made (e.g. Holyoak and Thagard 1995, pp. 35 ff.). Trump shows his audience the purpose of the fable by pointing out that there will be "problems" when people are "coming in" through the borders. The closest mapping to the predicted "problem" is the poisonous bite. Therefore, the purpose constraint must be fulfilled by mapping all those aspects that are inferentially connected to the event of the bite.

\subsection{Trump's fable as a source-analogue in an argument by analogy}

Trump's remarks before he presents his fable indicate that at least one of the purposes for which he wants to use it is to argue for the conclusion that immigrants cause problems (and that therefore stronger vetting is necessary): "We are going to have problems. We have to very, very carefully vet.", 18

In arguments by analogy, the purpose of the analogy is to support a transfer of elements through analogical inference. ${ }^{19}$ The

\footnotetext{
18 Trump, Rally in Harrisburg, Pennsylvania, April 29, 2017

19 This transfer happens through so-called copy and substitution: the relation (e.g. woman helps snake) that is supposed to be transferred is copied over into 
transfer is supported by the successful mapping of elements that the reasoner knows exist in the source and the target-analogue (e.g. the woman taking the snake in/the immigrants crossing the border). Through the inference, the step is made to the assumption that because the reasoner knows of a further element in the sourceanalogue (the snake biting the woman), there is also a corresponding element in the target-analogue (there will be problems). ${ }^{20}$ In his description of arguments by analogy, Andre Juthe has argued that an analogy is successful in providing support for such an analogical transfer when within the source-analogue (the fable), there will be elements that stand in such inferential connections to the sourceelement that is supposed to be transferred (the bite) that they determine it (e.g. the plea, the decision to help). If these elements can be successfully mapped onto the target-analogue (e.g. the petition, the decision to let immigrants cross the borders), then the analogy supports the transfer and thereby the conclusion (there will be problems) (Juthe 2005, pp. 4 ff.).

The purpose constraint is what allows analogies to be such effective rhetorical tools. An interlocutor understands an argument by analogy by allowing the purpose constraint to guide her mappings. ${ }^{21}$ Attempting to understand Trump's analogy, she will try to map the snake, the woman, the plea etc. - every element that is part of what leads to the bite. One of the effects of this attempt is that she is encouraged to pay special attention to those elements of the target-analogue that can be mapped successfully (but also to those elements that could not be mapped, the ones that are missing). These elements gain presence in the mind of the interlocutor; they step into the foreground and influence her impression of the target-

the target-analogue at the appropriate level of abstraction, and the two fillers (woman and snake) are substituted for their equivalents in the target (America and immigrants) (Holyoak and Thagard 1995, $30 \mathrm{ff}$ ).

${ }^{20}$ This is visible in argument schemes for argument by analogy as they have been proposed, for example, by Walton (2014):

Similarity Premise: Generally, case $C 1$ is similar to case $C 2$.

Base Premise: $A$ is true (false) in case $C 1$.

Conclusion: $A$ is true (false) in case $C 2$.

${ }^{21}$ As Bermejo-Luque puts it, the interlocutor herself "works out the alleged similarities between the two analogues" (Bermejo-Luque 2014, p. 8).

(C) Katharina Stevens. Informal Logic. Vol. 38, No.1 (2018), pp. 53-83. 
analogue more prominently than before. ${ }^{22}$ And, attention being a sparse commodity, presence is drawn away from other elements of the target-analogue.

An arguer who is aware of this effect can choose to describe the source-analogue by putting most emphasis on elements that will be easily mapped, directing her interlocutor's attention to them. In this way, the arguer influences the image of the target-analogue that the interlocutor will have after processing the analogy. If the arguer has chosen her source-analogue well, then for the interlocutor, those elements of the target-analogue that support the conclusion are endowed with more presence while all others have less. A good source-analogue influences the interlocutor's understanding of the target-analogue so that elements which can be used to support the conclusion are the center of attention, while all others fall into the background.

Fables, with their "single-minded concentration" (Blackham 1985 , p. 201) seem built for this foregrounding function. Due to their semi-abstract structure, they do not include any element that will not serve the purpose of presenting their message - the message that is supposed to be applied to the target-analogue. ${ }^{23}$ Where a fable achieves believability, the outcome of the interaction it describes - that which the fable demonstrates happens generally in such interactions - appears as following almost necessarily from the fact that the embodied character-traits interacted. The effect of a fable as a source-analogue is that the interlocutor will pick out only those aspects of the target-analogue that fit the fable's plot and only those character-traits that the fable concentrates on. These elements are thus given additional presence. The problem is that unlike source-analogues that use real-life cases, or other kinds of narratives (e.g. novels), the world of the fable is simple and out-

\footnotetext{
${ }^{22}$ See footnote 5 for a short introduction to the concept of presence.

${ }^{23}$ I will here avoid discussion regarding whether the fable, when used as a source-analogue, first establishes its general truth, and whether this truth is then applied to the target. Interested readers will find relevant arguments in the discussion about the place of deductive inference in arguments by analogy (Govier 1989; Waller 2001; Guarini 2004; Shecaria 2013; and Bermejo Luque 2014)
}

(C) Katharina Stevens. Informal Logic. Vol. 38, No.1 (2018), pp. 53-83. 
comes follow from interactions in almost analytical fashion. Mapping the target-analogue according to the fable has the tendency of making the real world appear similarly simple. Nothing in the fable points to possible complexities, as other source-analogues might. Of course, if only the character-traits depicted in the fable determined the actions of the target-analogue's actors, the outcome that the fable describes would plausibly be the result. The Farmer and the Snake describes what happens when viciousness and tenderheartedness interact. An interlocutor who is willing to see viciousness in immigrants and tender-heartedness in 'America' at all is encouraged, by the fable-as-source-analogue, to concentrate only on these character-traits, reducing real people to stereotypes. She is also encouraged to concentrate only on those actions and events described in the fable, forgetting, for example, about the low-paid work and many other contributions undocumented immigrants often make once they have arrived in America. Once this is achieved, Trump's 'problems' appear unavoidable. The conclusion that Trump's proposed measures to control immigration should be adopted is only a few, easy, argumentative steps away.

When combined, the presence-influencing effects of sourceanalogues and the semi-abstractness of fables become problematic. Analogies can have manipulative effects because they can be used to foreground only what is conducive to the conclusion that the arguer favours. Because fables contain no hint to the world's inherent complexity, when they are used as source-analogues, they become especially effective tools for illegitimate manipulation. Even if a fable-as-source-analogue is used with good intentions, the risk of being misleading remains. ${ }^{24}$ I do not mean to say that fables

\footnotetext{
${ }^{24}$ I think that this is a problem even when fables are used in analogical arguments propounding aims and conclusions we may agree upon. Imagine your expartner, who has treated you badly in the past, asks you to help him in a way that might make you vulnerable, for example, by using your good reputation to get him a job in your company. I might be right to be concerned that her/his bad character will lead her/him to ultimately hurt you (by damaging your good reputation), and I might legitimately argue that you should not trust her/him. Nonetheless, I would still be very hesitant to use the fable of the farmer and the snake as a source-analogue. The fable's effect would still be to make the world appear much simpler than it is. I would still run the risk of leading you away
}

(C) Katharina Stevens. Informal Logic. Vol. 38, No.1 (2018), pp. 53-83. 
cannot be used for legitimate arguments by analogy, but the careful choice of the target analogue becomes extremely important: Fables will tend to have an oversimplifying effect when they are used to make a point about complex matters, making multi-dimensional characters with mixed motivations appear as stereotypes driven by a single character-trait. To use a fable legitimately would require limiting the point it is supposed to make about a complex targetanalogue. It should either be pointed out directly that the argument by analogy is applicable only to one part of the issue at hand, or the fable should be used only as a partial source analogue in combination with others. ${ }^{25}$ Trump's use of The Farmer and the Snake is an illustration of what happens when neither precaution is taken: the fable as the sole source-analogue for a complex situation with real people encourages its audience to oversimplify the situation and de-humanize the people.

This analysis allows me to make two comments. First, I should point out that this risk in using fables as source-analogues is slightly different from the one Govier and Ayers identify (2012, p. 27). Their criticism is the same as that of fables as arguments by instantiation. Again, they argue that the danger lies in the uniqueness of the situations that parables (which, to them, include fables) describe, and in the likely existence of relevant differences between their highly specific subject matter and the target-subject matter.

from a careful consideration of the various aspects of the situation, towards an oversimplified view in which the conclusion that you should not help appears as if it follows almost analytically.

${ }^{25}$ For the reasons discussed above, an argument by analogy with a fable as the source-analogue can generally be expected to be too weak to cogently establish a conclusion about a complex situation on its own. It is more likely that such an argument by analogy can be successful if it is presented together with further arguments that show that the invariably unaccounted-for aspects of the situation also support (or at least do not interfere with) the conclusion. Such further arguments could also be arguments by analogy, so that multiple sourceanalogues work together. What I have in mind would not be an argument by analogy with multiple, blended source-analogues as Marcello Guarini discusses (2010). Rather, it would be a linked argument as Guarini mentions briefly at the beginning of that paper, in which there are multiple arguments by analogy that are together strong enough to meet the burden of proof, but each too weak to do so on its own.

(C) Katharina Stevens. Informal Logic. Vol. 38, No.1 (2018), pp. 53-83. 
My objection is the same as before: because of the fable's semiabstract form, I do not believe that the problem is the specificity of the fable. Rather, the risk lies in the suppression of highly relevant elements in a target-analogue and in the fact that unlike other source-analogues (which also highlight certain aspects), the fable contains no hint that the world is complex and multi-faceted.

Second, it gives me opportunity to suggest an amendment to Plumer's (2016) analysis that the shorter a narrative, the easier it lends itself to "evil" argumentative uses. I think he is right when he suggests this might be because longer narratives are more dense, complex and have a high degree of detail. However, I do not think that it is the length of a narrative that makes it more or less prone to "evil" uses. ${ }^{26}$ Rather, I think that as the example of fables demonstrates, it is the degree of abstractness the narrative reaches that makes it vulnerable for abuse. If a narrative is semi-abstract, using particulars without distinguishing qualities - like fables do -, then it makes the world appear simple and predictable, discouraging a careful search for complicating factors.

\subsection{The problem with "viciousness"}

In Trump's case, the suppression of highly relevant elements in the target-analogue is not the only problem. He wants to show that immigrants will cause problems, but his fable portrays the interaction between character-traits, and the snake's bite is the consequence of this interaction. Therefore, the possession of the character-traits by the relevant actors in the target-analogue is required for the argument by analogy to work. Indeed, it is possibly the only irreplaceable necessary similarity, given that the situation in which tender-heartedness and viciousness interact could vary without a change in the outcome (that the tender-hearted will be betrayed by the vicious). That immigrants are (likely to be) vicious should therefore be a necessary premise for the argument to work. Of course, this cannot be defended, and Trump does not attempt to do

\footnotetext{
${ }^{26}$ Some fables (e.g., Animal Farm, Orwell 1945) are rather long and some short stories (e.g., The Dinner Party, Ferris 2008) are highly complex and portray three-dimensional characters.
} 
so directly. But the fable is effective as an argumentative sourceanalogue anyway. ${ }^{27}$ The question is, why?

Part of the reason lies in the kind of narrative the fable is. The main emphasis in any fable is on the plot. Indeed, it is the plot through which the fable typically delivers its message (Blackham 1985 , p. xviii). In our case, the plot consists of the finding of the snake that needs help, the decision to help by taking the snake into the home, and the resultant bite. ${ }^{28}$ This is where Trump's audience can easily find appropriate mappings - the immigrants that need help and the decision to help by allowing them to enter America. Even the snake's bite can be mapped. As I mentioned briefly in the introduction, Trump provides anecdotes of victims of violence perpetrated by immigrants before he reads the fable. At his rally in Harrisburg, he speaks of visiting the victims of gangs formed by South-American immigrants. At earlier rallies, he has spoken about terrorist attacks, linking them with references to refugees. ${ }^{29}$ These accounts appear as simple anecdotes when he tells them, but they prepare his audience to take them up as independent reasons for assuming that immigrants will cause problems once Trump announces his conclusion and reads the fable. By telling his anecdotes, Trump has slipped in certain images and ideas about immigrants that prepare his audience for accepting a narrative about the effects of allowing immigrants to enter America that runs parallel to the plot of his snake-fable.

Supplying these anecdotes solves the viciousness-problem. Fables, as narratives, form coherent wholes. Unlike other arguments, they are not organized to move from premises to an identified conclusion and therefore do not pre-determine the direction reasoning based on them will go. ${ }^{30} \mathrm{~A}$ believable fable supports the

\footnotetext{
${ }^{27}$ His offer to read the fable is met by the cheers of those who have encountered it at earlier rallies. There are intermittent cheers throughout the poem accompanied by clapping, yelling, and cheering at the end. The audience behind Trump can be seen smiling and nodding at the moment of the snake-bite.

${ }_{28}$ Also important is the taunting remark by the snake at the end.

${ }^{29}$ Rallies in: Harrisburg, April 29, 2017; Cedar Falls Iowa, January 12, 2016; Estero Florida, September 19, 2016.

${ }^{30}$ Bex and Verheij point out that unlike other arguments, the elements of a (argumentative) narrative are portrayed holistically as integrated parts of a 
conclusion that certain kinds of outcomes will follow from the interaction of certain kinds of character-traits. But it equally supports the move in the opposite direction: that certain types of behaviours and outcomes are a sign of the existence of certain character-traits. Looking back at the scheme Plumer offers for narrative arguments, we can observe that the conclusion he proposes refers vaguely to the principles that would have to operate in the world for the narrative to be believable. This is no mistake in the scheme. Narratives tend to portray more than one principle at once, and fables are no exception. The Farmer and the Snake supports "Kindness to the vicious will be met by betrayal" as strongly as "Where kindness is met by betrayal, viciousness is likely involved."

With Trump's anecdotes of immigrant-violence in place to complete the mapping of the plot-elements, the fable now supports the analogical inference that immigrants are vicious. By itself, the analogy would have to support two inferential transfers: from the viciousness of the snake to the viciousness of the immigrants and from the snake's bite to the problems the immigrants cause. That would make it fail. What saves it is that Trump has given some independent (though questionable) reasons for believing that immigrants pose a risk through his anecdotes. But now Trump's conclusion that immigrants will cause problems also fulfills the role of a premise. The argument is circular.

This circularity, however, does not take away from the fable's potential for increasing the audiences' assent to the conclusion that immigrants will cause problems. Again, it is the semi-abstract nature of the fable and the resulting way in which its conclusion follows almost analytically from the character-traits that it examines that becomes effective. For the fable does not so much support the claim that sometimes, some immigrants cause problems. ${ }^{31}$ Rather, by integrating the arising of a problem into a coherent narrative, it succeeds in transferring the felt necessity with which

whole, rather than atomistically as premises that can make sense on their own. (Bex and Verheij 2011)

31 This would hardly be surprising. People sometimes cause problems, and immigrants are people. 
the snake-bite happens to the relationship of America with its (potential) immigrants (Trump says: “(...) we know what we are going to have. We are going to have problems"). The fable enables Trump to causally connect elements that his audience already accepts - potential immigrants need help; America admits immigrants; but also, immigrants commit crimes/cause problems -by providing the driving motive of viciousness. It provides a kind of explanatory ordering that makes sense of these different, accepted elements. How this ordering can work is described by Bex and Verheij (2011): narratives succeed in giving an account of how real events are to be understood if they are internally and externally coherent and if each element of the story that refers to facts is supported through arguments from evidence. The role of the fable is to lend believability to the story scheme [ $\mathrm{V}(\mathrm{x})$ needs help \& $(\mathrm{T}) \mathrm{y}$ helps $(\mathrm{V}) \mathrm{x} \rightarrow(\mathrm{V}) \mathrm{x}$ causes problem for $(\mathrm{T}) \mathrm{y} . \mathrm{V}=$ vicious; $\mathrm{T}=$ tender-hearted]. This scheme orders the relationship between America and its (potential) immigrants into a story that is felt to be coherent. $^{32}$ By combining this seeming coherence with his anecdotal evidence, Trump accomplishes the appearance of fulfilling Bex and Verheij's conditions and establishes a narrative according to which admitting immigrants that need help leads, with necessity, to problems.

\subsection{Trump's fable as a source-analogue in a frame-setting analogy}

Trump's fable makes his conclusion appear necessary because it provides a narrative that explains to his audience how (some) immigrants who were admitted into America ended up committing crimes: ${ }^{33}$ immigrants are vicious, and it is the nature of the vicious to betray kindness. However, this is not the only thing the fable achieves. Trump's trick around viciousness, together with the

\footnotetext{
${ }^{32}$ For a more in-depth analysis of the connection between analogies and storyschemes, see Walton $(2010,2012)$. I do not agree with Walton that all arguments from analogy should be analyzed using story-schemes (see Stevens 2018, footnote 16 ), but his analysis is certainly useful where source-analogues are plotdriven.

${ }^{33}$ Compare Hans Hansen's analysis of the difference between a chronology and a narrative (Hansen 2017).
} 
fable's oversimplifying effect, achieves a change in the frame that Trump's audience accepts and perceives immigrants (and the people willing to help them) in.

The importance of creating, influencing, and changing the frames in which audiences perceive subject matters for political argumentation has been acknowledged in argumentation theory and rhetoric (e.g. by David Zarefsky 1998, 2004, 2006), but also by political activists (like the cognitive scientist and linguist George Lakoff, e.g. 2016). I will here use Harald Wohlrapp's analysis because to my knowledge, he has paid the most detailed attention to the role that frames play in argumentation by making them a central issue in his theory of argumentation (Wohlrapp 2014).

The functioning of frames in argumentation can be made accessible via Wohlrapp's analysis of the famous duck-rabbit head (2014 p. 191). ${ }^{34}$ The duck-rabbit head is an ambiguous image that can be seen as either depicting a rabbit or a duck. There are three frames available that we can use to talk about the duck-rabbit head: [as duck], [as rabbit], [as ambiguous image]. The frame [as ambiguous

${ }^{34}$ For those readers who do not know the duck-rabbit head, an image can be found under: https://richardwiseman.wordpress.com/2011/12/21/worlds-bestduck-rabbit-illusion/ Because the duck-rabbit head is an ambiguous image, it is convenient as an example to explain how frames work, and that is how I use it here. However, what makes it such an easily accessible example - that every reader can easily experience the switch between seeing the duck and seeing the rabbit, even if they already know what kind of image this is-also has a couple of disadvantages. On the one hand, this example exaggerates the effect that frames have on thinking. Most people are not able to see the duck and the rabbit at the same time, even if they know of both. Frames that we know of do not necessarily control our mind in this way. The example below, about my mother, shows this. Even though I think of her in one or the other of the two frames I describe, this does not mean that I necessarily ever think of her exclusively in one frame, in the way that at any one point in time most people exclusively see either the duck or the rabbit. On the other hand, once we realize that both the duck and the rabbit can be seen in the duck-rabbit head, we are unlikely to persist in our claim that it is really the picture of a duck. Frames, like the one I will argue is established by Trump's fable, can discipline thought even after they have been recognized as a frame with alternatives. Even if Trump's audience realizes that others might see immigrants in a different light, they might still persist in their almost exclusive usage of one frame only. I thank an anonymous reviewer for her/his comment to this effect.

(C) Katharina Stevens. Informal Logic. Vol. 38, No.1 (2018), pp. 53-83. 
image] holds together and orders the two other frames (2014, p. 184). For someone who has only ever seen the duck-rabbit head [as duck], the duck-rabbit head simply shows a duck. For someone who has seen both duck and rabbit and knows of the availability of the [as ambiguous image] frame, the [as duck] frame is simply an aspect of the duck-rabbit head. Given that we see everything [as something] and nothing just as it is in itself, frames are omnipresent in our understanding of the world.

Each frame comes with what Wohlrapp calls an "inferential potential" (2014, p. 188): Each frame allows certain inferences to be made about its object and forbids others. In the frame [as rabbit], it makes sense to say about the duck-rabbit head, "This picture is bad: the ears are too long." In the frame [as duck] this does not make sense. Similarly, "The animal in this picture lays eggs," is correct in the frame [as duck], but patently false in the frame [as rabbit]. Through the inferential potential, the frame in which we see a subject matter controls the kinds of arguments about it we will accept, or even understand. We will reject an argument that makes use of inferences not allowed in the frame we have adopted. Arguments making use of inferences the frame allows will be received favorably. Where we have access to several frames for a subject matter-where we can perceive different aspects of it or take different perspectives on it-, we can understand arguments made from different frames. Nonetheless, we will not accept all of them equally. Usually, the aspects of a subject matter that we know are ordered somehow. Sometimes, this is the case because we have evaluated several frames and assigned a hierarchy. An ethically motivated vegetarian knows that pigs can be seen [as proteinsource], but has subordinated this frame to the frame [as moral patient/agent]. Other times, one of our frames simply has more presence in our minds than others. I think of Elke von Radziewsky more readily [as my mother] than [as editorial journalist]. But this is only so because that is the frame I most often use when I relate to her, not because I think that any hierarchy between the two is justified. Nonetheless, the mere fact that the frame [as my mother] has more presence in my mind means that I will find it easier to formu- 
late or accept arguments about Elke von Radziewsky that make use of its inferential potential. ${ }^{35}$

This short discussion of the role of frames in argumentation should suffice to show why influencing the frames is extremely important in political argumentation. An arguer who succeeds in exerting control over the kind of frame that will have most presence in the minds of voters has gained a lot of ground. She influences the inferences voters are likely to make about the subject matter and the arguments they will likely find convincing. She can ensure for herself that they will be drawn to approve of all those conclusions (and decisions and actions based on them) that are enabled through the frame's inferential potential.

Earlier, I described how a well-chosen source-analogue can influence the presence that certain elements of the target-analogue will have in the interlocutor's mind. Through it, an arguer can influence the interlocutor's understanding of the target such that it becomes more favorable for the comparison to the sourceanalogue. In other words, the arguer can influence the frame in which the target is thought about. Trump's choice to present the claim that immigrants will cause problems as the conclusion of his argument provides his analogy with a purpose that leads directly to a re-framing of immigrants, as well as those who help them. To understand the analogy, his audience maps the two analogues under fulfillment of the purpose-constraint. But this is only possible if the two mapped protagonists of the target-analogue, in this case America and immigrants, are thought about in frames with the inferential potential that allows the inference to problems occurring necessari$l y .{ }^{36}$ Once the mapping has been accomplished, the immigrants appear in a frame that we can name [as snake] and America (if it

\footnotetext{
${ }^{35}$ For a more in-depth discussion of Wohlrapp's theory of frames and its relation to rhetoric, see Stevens (2017). For a more informative work on frames in general, see Goffman (1974).

${ }^{36}$ This is a variation of what Jason Stanley describes as the smuggling in of nonat-issue content in propaganda (Stanley 2015, chapter 4). It would have been an interesting exercise to analyze Trump's use of the fable as a piece of propaganda a la Stanley, but space does not permit. However, much of what Stanley describes in Chapter 4 of his book will be recognizable in Trump's use of the snake-fable.
} 
allows immigrants to enter) appears in the corresponding frame [as tender-hearted woman]. While the names of these two frames are arbitrary, their inferential potentials are not. The frame [as snake] connects immigrants to viciousness, betrayal etc., and to the inferences that can be drawn from those associations in varying contexts. $^{37}$ The frame [as tender-hearted-woman] connects the potential America that admits immigrants to the prospect of being betrayed, but also to naïveté and excessive softness: "You knew damn well I was a snake before you took me in". The woman knew what kind of animal the snake was, and presumably, the American people should know what kinds of people immigrants are. Taking in either is naïve and soft, character traits that stand in stark contrast to the way Trump claims America has to be: "We have to be smart, we have to be vigilant." 38

If Trump's audience takes his snake-fable as grounds for strengthening their belief that immigrants lead to problems, then they have also accepted these two frames as adequate ways to understand immigrants and those who help them. Moreover, not only have these frames been understood as possible by his audience, they have also been used in a coherent explanation for why immigrants commit crimes. According to Wohlrapp, a frame becomes acceptable for us where it explains and coherently integrates our experiences (Wohlrapp 2014, pp. 369 ff.). Trump's fable does its work through providing an explanatory, coherent account of the

\footnotetext{
${ }^{37}$ I do not want to commit myself to saying that what Trump is doing here falls under the concept of a persuasive definition as the concept was introduced by Stevenson (1938) and developed further by Walton (2005) and Walton and Macagno (2010). Zarefsky makes the connection between framing and defining, but his concept of frames is somewhat different from that of Wohlrapp (1998, 2004, 2006). In any case, I think that Trump uses the fable at least for a very similar kind of move.

${ }^{38}$ Paraphrased from the rally in Harrisburg, Pennsylvania, July 29, 2017, where directly before the reading of the fable Trump stated, "We gotta get tough, we gotta be smart, we gotta be vigilant. We gotta know who the hell is coming into our country. Ok? We gotta be vigilant." At the beginning of the rally in Cedar Falls Iowa, January 12, 2016, some time before the reading of the fable, Trump stated, "It's amazing, it's going to happen unless we get very, very smart." $\mathrm{He}$ made similar remarks at the rally in Estero Florida, on September 19, 2016 right after reading the fable.
} 
relationship between America and its immigrants. Therefore, the use of the frames in the argument not only provides the conclusion of the argument, but also the frames themselves with plausibility. Once this is accomplished, Trump has secured more than just the likelihood of assent to his propositions about the treatment of immigrants (e.g. more careful vetting). He has also heightened the likelihood of assent for further policies and decisions that can be argued for by using the inferential potential of those frames. ${ }^{39}$

In a paper on strategic maneuvering through multi-purpose arguments, Dima Mohammed argues that arguments that succeed in making contributions to more than one issue allow their creators to defend points without having to make them explicit (Mohammed 2016, p. 132). Trump's use of The Farmer and the Snake accomplishes this very effectively. By overtly making a claim about the necessity of strict vetting, Trump is also able to gain assent for the framing of immigrants [as snake] and those wanting to help [as tender-hearted woman]. Openly claiming such an association or asserting some of the inferences available through the inferential potential of these frames would have likely been met with even more resistance than the claim that immigrants cause problems. After all, the frame [as snake] is patently demonizing and dehumanizing. Trump is known for making statements other public speakers might have shied away from, but here he has chosen the more effective path of employing a multi-purpose argumentative move.

\footnotetext{
${ }^{39}$ Indeed, given that the fable of the snake is highly memorable, but in no way restricted to immigrants, once the connections it suggests are accepted, these frames can easily be transferred to other situations in which America faces the choice to help those in need.

As an aside, because he has linked the use of the fable with the adjectives "smart" and "vigilant", he can call these frames back to the attention of his audience without having to refer to any part of the fable at all. This he might have accomplished, for example, when he tweeted "We need to be smart, vigilant and tough. We need the courts to give us back our rights. We need the Travel Ban as an extra level of safety!" in reaction to attacks in London in June 2017. (Twitter: @realDonaldTrump June 3, 2017:

https://twitter.com/realDonaldTrump/status/871143765473406976)
}

(C) Katharina Stevens. Informal Logic. Vol. 38, No.1 (2018), pp. 53-83. 


\section{Conclusion}

This paper is written as an analysis of Trump's use of the snake fable. By providing insight into one way in which Trump accomplishes the demonizing of immigrants in his audiences' minds I hope to have added a puzzle-piece to the answer of how he and others manage to accomplish this in general.

This paper is also meant to make a contribution to the inquiry into how narratives can work as arguments. Here, the topic is the use of fables in argumentative analogies. I do not think that fables make for bad Plumerian arguments, nor do I want to say that legitimately using a fable as a source analogue in an argument by analogy is impossible. Trump's use of The Farmer and The Snake is certainly an extreme example of an illegitimate use of a fable as a source-analogue, given that he uses the fable together with anecdotes that serve to smuggle the attribute "vicious" in. However, I do think that the semi-abstract form of fables makes them a risky choice as a source analogue when dealing with a complex real-life issue, even if the needed equivalents are actually there. This is especially so where the fable is used as the only source analogue to make a point about a whole issue, instead of as one of several source-analogues, or about only one aspect of an issue. Fables are highly simplified narratives, featuring one-dimensional characters and foreseeable plot-lines. This is not a weakness of the fable. It is, however, a feature that makes them highly efficient for transferring presence to specific aspects of a complex situation, making it appear much simpler than it is. Especially risky is that fables use characters with often only one or two character-trait(s). Where the fable is used as a source-analogue for a situation in which real people interact, this will encourage the audience of the analogy to engage in stereotyping and potentially de-humanizing thinking about these protagonists. These are reasons to be very careful around fables as source-analogues in argumentation. 


\section{References}

Aesop. The farmer and the snake. URL accessed 7 July 2017: $<$ http://mythfolklore.net/aesopica/perry/176.htm>

Aesop. 2017. The fox and the crow. URL accessed 25 July 2017: $<$ http://www.eastoftheweb.com/shortstories/UBooks/FoxCrow.shtml>

Aristotle. 2010. Rhetoric. Edward Meredith Cope and John Edwin Sandys (transl.) Cambridge: Cambrige University Press.

Bermejo-Luque, Lilian. 2012. A unitary schema for arguments by analogy. Informal Logic 32(1): 1-24.

Bex, F. 2009. Analysing stories using schemes. In Legal Evidence and Proof: Statistics, Stories, Logic, eds. H. Kaptein, H. Prakken and B. Verheij, 93-116. Farnham: Ashgate.

Bex, F. and Verheij. 2011. Arguments, stories and evidence: Critical questions for fact finding. In The Seventh Conference of the International Society for the Study of Argumentation (ISSA), eds. F. H. van Eemeren, B. Garssen, D. Godden \& G. Mitchell. Amsterdam: Sic Sat.

Blackham, H.J. 1985. The fable as literature. London: The Athlone Press.

De Bustos, Eduardo. 2017. Parables: Crossroads between the cognitive theory of metaphor and argumentation theory. In Narration as argument, ed. Paula Olmos, 83-99. Cham, Switzerland: Springer.

Ferris, Joshua. 2008. The dinner party. In The New Yorker, 11 August 2008

Fisher, W.R. 1987. Human communication as narration. Toward a philosophy of reason, value, and action. Columbia: University of South Carolina Press.

Fontaine, Jean de La. 2001. Fables. Edward Howard Marsh (ed.). New York: Knopf.

Genter, Dedre. 1983. Structure mapping, A theoretical framework for analogy. Cognitive Science 7(2): 155-170.

Goffman, Erving. 1974. Frame analysis: An essay on the organization of experience. Reprinted 2010. Boston: Northeastern University Press.

Govier, Trudy. 1989. Analogies and missing premises. Informal Logic 11(3): 141-152.

Govier, Trudy and Ayers, Lowell. 2012. Logic, parables and argument. Informal Logic 32(2): 161-189.

Guarini, Marcello. 2004. A defense of non-deductive reconstructions of analogical arguments. Informal Logic 24(2): 153-168. 
Guarini, Marcello. 2010. Understanding blended multi-source arguments as arguments from partial analogies. Ratio Juris 23(1): 65-100.

Hansen, Hans. 2017. Narrative arguments as a kind. Presentation at ECA June 2017, Freibourg.

Holyoak, Keith J. and Thagard, Paul. 1989. Analogical mapping by constraint satisfaction. Cognitive Science 13(3): 295-355.

Holyoak, Keith, J. and Thagard, Paul. 1995. Mental leaps: Analogy in creative thought. Cambridge, MA.: MIT Press.

Hunt, Lester H. 2009. Literature as fable, fable as argument. Philosophy and Literature 33(2): 369-385.

Juthe, Andre. 2005. Argument by analogy. Argumentation 19(1): 1-27.

Lakoff, George. 2016. Moral politics: How liberals and conservatives think. Chicago/London: The University of Chicago Press.

Lessing, Gotthold Ephraim. 1759. Abhandlung über die Fabel. URL accessed 8 August 2017:

$<$ http://gutenberg.spiegel.de/buch/abhandlungen-uber-die-fabel$1168 / 1>$

Mohammed, Dima. 2015. Goals in argumentation: A proposal for the analysis and evaluation of public political arguments. Argumentation 30(3): 221-245.

Mohammed, Dima. 2016. It is true that security and Schengen go hand in hand. Strategic manoeuvring in the multi-layered activity type of European Parliamentary debates. In Dialogues in Argumentation. Windsor Studies in Argumentation, ed. R. von Borg, URL accessed 18 February 2018:

https://windsor.scholarsportal.info/omp/index.php/wsia/catalog/book/12: 232-266.

Nussbaum, Martha. 1995. Poetic justice. Boston: Beacon Press.

Olmos, Paula. 2014. Classical fables as arguments: Narration and analogy. In Systematic approaches to argument by analogy, ed. Henrique Jales Ribeiro, 189-208. Cham: Springer.

Olmos, Paula. 2015. Story credibility in narrative argument. In Reflections on Theoretical Issues in Argumentation Theory. Argumentation Library 28, eds. F.H. van Eemeren and B. Garssen. Cham: Springer.

Orwell, George. 1945. Animal Farm. Reprinted 2008. London: Penguin Books.

Perelman, Chaïm. 1982. The realm of rhetoric. London: University Notre Dame Press.

Perelman, Chaim and Olbrechts-Tyteca, Lucy. 1969. The new rhetoric. Lanham, MD: The University Press of America. 
Plumer, Gilbert. 2015. On novels as arguments. Informal Logic. 35(4): 488-507.

Plumer, Gilbert. 2016. Argumentatively evil storytelling. In Argumentation and Reasoned Action - Proceedings of the 1st European Conference on Argumentation, eds. Dima Mohammed and Marcin Lewinski. London: College Publications.

Shecaira, Fabio. 2013. Analogical arguments in ethics and law: A defense of a deductivist analysis. Informal Logic 33(3): 406-437.

Stanley, Jason. 2015. How propaganda works. Princeton, New Jersey/Oxford: Princeton University Press

Stevens, Katharina. 2017. Does rhetoric have a place in Wohlrapp's theory of argumentation? Informal Logic 37(3): 183-210.

Stevens, Katharina. 2018. Case-To-Case Arguments. Argumentation Online first. URL accessed 18 February 2018: https://link.springer.com/article/10.1007/s10503-018-9448-z

Stevenson, C. L. 1938. Persuasive definitions. Mind 47(187): 331-350.

Tindale, Christopher. 2015. The philosophy of argument and audience reception. Cambridge: Cambridge University Press.

Toulmin, S. 1969. The uses of argument, Cambridge: Cambridge University Press.

Trump, Donald. 1/12/2016. Rally in Cedar Falls, Iowa, URL accessed 16 February 2018: $<$ https://www.youtube.com/watch?v=mqYG2SVpaac $>$

Trump, Donald. 9/19/2016. Rally in Estero, Florida. URL accessed 16 February 2018: <https://www.youtube.com/watch?v=bs 7a4hyqQY>

Trump, Donald. 4/29/2017. Rally Harrisburg, Pennsylvania. URL accessed 16 February 2018: $<$ https://www.youtube.com/watch?v=40iJUAHej14>

Walton, Douglas. 2005. Deceptive arguments containing persuasive language and persuasive definitions. Argumentation 19(1): 159-186.

Walton, Douglas, 2010. Similarity, precedent and argument from analogy. Artificial Intelligence and Law 18(3): 217-246.

Walton, Douglas. 2012. Story similarity in arguments from analogy. Informal Logic 32(2): 190-221.

Walton, Douglas. 2014. Argumentation schemes for argument from analogy. In: Systematic Approaches to Argument by Analogy, ed. Henrique Jales Ribeiro, 23-40. Cham: Springer.

Walton, Douglas and Macagno, Fabrizio. 2010. What we hide in words: Emotive words and persuasive definitions. Journal of Pragmatics 42(7): 1997-2013. 
Waller, Bruce N. 2001. Classifying and analyzing analogies. Informal Logic 21(3): 199-218.

Wilson, Al. 1968. "The Snake". The Snake. Vinyl. Bell Records.

Wohlrapp, Harald. 2014. The concept of argument. Dortrecht: Springer.

Zarefsky, David. 1998. Definitions. Argument in a time of change. In Definitions, frameworks, and critiques, ed. James F. Klumpp. Annandale, VA: National Communication Association: 1-11.

Zarefsky, David. 2004. Presidential rhetoric and the power of definition. Presidential Studies Quarterly 34(3): 607-619.

Zarefsky, David. 2006. Strategic maneuvering through persuasive definitions: Implications for dialectic and rhetoric. Argumentation 20(4): 399-416. 